\title{
Association Between Previous Statin Use and Alzheimer's Disease: A Nested Case-control Study Using a National Health Screening Cohort
}

\section{Ji Hee Kim}

Hallym University College of Medicine

Heui Seung Lee

Hallym University College of Medicine

Jee Hye Wee

Hallym University College of Medicine

Chan Yang Min

Hallym University College of Medicine

\section{Dae Myoung Yoo}

Hallym University College of Medicine

Hyo Geun Choi ( $\nabla$ pupen@naver.com )

Hallym University College of Medicine https://orcid.org/0000-0003-1655-9549

\section{Research}

Keywords: Alzheimer's disease, Cholesterol, Dementia, Neurodegenerative dementia, Risk factor, Statin

Posted Date: October 1st, 2020

DOl: https://doi.org/10.21203/rs.3.rs-83306/v1

License: (9) (i) This work is licensed under a Creative Commons Attribution 4.0 International License. Read Full License 


\section{Abstract}

\section{Background}

A number of studies on the incidence of Alzheimer's disease (AD) in patients taking statins have been reported; however, the results are inconsistent. This study aimed to investigate the association between previous statin use and the risk of AD development in Korean residents.

\section{Methods}

We assessed the Korean National Health Insurance Service-National Sample Cohort, which includes individuals aged older than 40 years from 2002 to 2015. A total of 17,172 AD patients were matched by age, sex, income, and region of residence with 68,688 control participants at a ratio of 1:4. We used a multiple conditional logistic regression model to analyze the association between the number of days of statin use and $A D$ occurrence. Further analyses were performed to identify whether this association was maintained for different ages, sexes, socioeconomic statuses, and covariates.

\section{Results}

The adjusted odds ratio (OR), which was adjusted for potential confounders, for the days of statin use per year in the AD group compared to the control group was 0.95 (95\% confidence interval $[C I]=0.92-0.98, P$ $=0.003)$. The number of days of statin use in the AD group was significantly smaller than that in control group among women older than 75 years and in the subgroups of nonsmokers and individuals with normal weight, alcohol consumption less than once a week, total cholesterol level below 200, systolic blood pressure below 140 and diastolic blood pressure below 90, and fasting blood glucose below 100 .

\section{Conclusions}

Our results suggested that statin use may prevent the occurrence of $A D$. The effect of preventing $A D$ in statin use may be greater in individuals with relatively low risk.

\section{Background}

Alzheimer's disease (AD) is not only the most common form of dementia but also the most common cause of neurodegenerative dementia among elderly individuals, accounting for approximately $60 \%$ or more of all people with dementia[1]. With an estimated prevalence of 46.8 million cases worldwide in 2015 , the number of patients with $A D$ is expected to continue to increase in the coming years[2]. This rapidly increasing disease burden is challenging healthcare and socioeconomic systems worldwide. Despite substantial research and development investment in AD, none of the currently available medications prevents AD or modifies its pathology. To date, therapeutic approaches for diseasemodifying effects have focused on targeting the amyloid cascade, attempting to prevent the accumulation of toxic amyloid aggregates. However, recent clinical trials in AD, many based on the 
amyloid hypothesis, have been disappointing, and this has increased interest in other potential therapeutic avenues[3].

Statins are the most widely prescribed Food and Drug Administration (FDA)-approved cholesterollowering medications[4], and they are 3-hydroxy-3-methylglutaryl coenzyme A reductase inhibitors that reduce cholesterol synthesis and upregulate low-density lipoprotein (LDL) receptors in hepatocyte membranes, enabling greater clearance of LDL from the bloodstream and lowering the level of lipoproteins[2]. Beyond their cholesterol-lowering effect, statins have demonstrated various additional effects, including antioxidant, anti-inflammatory, antithrombotic, anti-excitotoxicity, and angiogenesispromoting effects; the improvement of vascular endothelial function; and the modulation of amyloid and tau metabolism[5-8]. Consequently, several studies have examined the possible benefits of statins in preventing or reducing the risk of $A D$ and dementia. Among all causes of dementia, vascular dementia is the one type that is more likely to benefit from statins since vascular dementia is known to share the same risk factors as ischemic stroke, and both elevated levels of serum total cholesterol and LDL and decreased levels of high-density lipoprotein (HDL) have been associated with the risk for vascular dementia.[9] However, the role of statins in the improvement of cognitive function and the prevention of $A D$ is still quite debatable.

Therefore, this study aimed to examine the association between previous statin use and the incidence of $A D$ while adjusting for putative risk factors for $A D$ occurrence. We additionally assessed whether these associations were consistent for different groups in a subgroup analysis stratified by age; sex; socioeconomic factors, such as income and region of residence; and baseline medical comorbidities, including dyslipidemia, total cholesterol, obesity, smoking status, alcohol consumption, blood pressure, and fasting blood glucose.

\section{Methods}

\section{Study Population}

This study was approved by the Institutional Review Board (IRB) of the ethics committee of Hallym University (IRB No. 2019-10-023). The need to obtain informed consent was waived by the IRB owing to the use of deidentified claims data. All analyses adhered to the guidelines and regulations of the ethics committee of Hallym University. A detailed description of the Korean National Health Insurance Service (NHIS)-Health Screening Cohort data has been delineated elsewhere.[10]

\section{The Number of Days of Statin Use (Exposure)}

The sum of the total days of statin prescription was continuously counted for 2 years (730 days) before the index dates. Atorvastatin, fluvastatin, lovastatin, pitavastatin, pravastatin, rosuvastatin, and simvastatin were included.

\section{Alzheimer's Disease (Outcome)}


Participants were considered to have AD if they were diagnosed with Alzheimer's disease (ICD-10 code: G30) or dementia in Alzheimer's disease (F00). To ensure the accuracy of the diagnosis, we selected only the participants who were treated $\geq 2$ times, as we did in our earlier studies.[11,12] We provide a description of the reliability of the diagnosis of dementia in Additional file 1.

\section{Participant Selection}

AD patients were selected from a total of 514,866 participants with $615,488,428$ medical claim codes $(n=$ $20,087)$. The control group comprised all participants who were not dementia patients $(n=494,779)$. To include $A D$ patients who were diagnosed for the first time, we excluded $A D$ patients who were diagnosed from 2002 to 2003 (washout period, $n=407$ ). The participants were excluded if they were $<60$ years old ( $n=661$ for dementia patients, $n=179,499$ for control participants). Control participants with ICD-10 codes of G30 or F00 from 2002 through 2015 were excluded $(n=5,209)$. Participants for whom total cholesterol records ( $n=15$ for dementia patients), blood pressure records ( $n=2$ for dementia patients), fasting blood glucose records ( $n=1$ for dementia patients), or body mass index $\left(B M l, k g / m^{2}\right)$ records $(n=$ 2 for dementia patients) were not present were excluded. AD patients were matched with control participants at a ratio of 1:4 for age, sex, income, and region of residence. To curtail selection bias, the control participants were selected in random number order. The index date of each AD patient was set as the time of the treatment of dementia. The index date of each control participant was fixed as the index date of their matched AD patient. Therefore, each matched AD patient and control participant had the same index date. During the matching process, 1,827 AD patients and 241,383 control participants were excluded. Ultimately, 17,172 AD patients were matched with 68,688 control participants (a ratio of 1:4) (Fig. 1).

\section{Covariates}

Age groups were divided into 5-year intervals: 60-64, 65-69, 70-74..., and 85+ years old (total of 6 age groups). Income groups were classified into 5 classes (class 1 [lowest income]-5 [highest income]). The region of residence was sorted into urban and rural areas, as in our previous research.[13] Tobacco smoking, alcohol consumption, and obesity (determined using BMI) were categorized in the same manner as in our previous study.[14] Systolic blood pressure (SBP), diastolic blood pressure (DBP), fasting blood glucose, and total cholesterol were measured. A participant was considered to have dyslipidemia if an ICD-10 code of E78 was present $\geq 2$ times before the index date. The Charlson Comorbidity Index (CCI) has been used extensively to assess disease burden using 17 comorbidities as the continuous variable ( 0 [no comorbidities] through 29 [multiple comorbidities]).[15] CCl scores were calculated for all comorbidities except for dementia.

\section{Statistical Analyses}

The general characteristics of the $A D$ and control groups were compared using the chi-square test for categorical variables and the independent $t$ test for continuous variables. 
To analyze the odds ratios (ORs) with $95 \%$ confidence intervals (Cls) for the days of statin use per year in AD patients compared to control participants, conditional logistic regression was used. In this analysis, the crude model, model 1 (adjusted for dyslipidemia history, total cholesterol, SBP, DBP, and fasting blood glucose), and model 2 (adjusted for model 1 plus obesity, smoking, alcohol consumption, and $\mathrm{CCl}$ scores) were determined. The analysis was stratified by age, sex, income (lower income [1-3] and high income [45]), and region of residence.

For the subgroup analyses, we divided participants by age and sex ( $<75$ years old and $\geq 75$ years old; men and women) and analyzed the crude model, model 1, and model 2. Additionally, another subgroup analysis based on obesity status (underweight, normal weight, overweight, and obese [obese I and II]) was performed using unconditional logistic regression. In these analyses, model 1 (adjusted for age, sex, income, and region of residence), model 2 (adjusted for model 1 plus dyslipidemia history, total cholesterol, SBP, DBP, and fasting blood glucose), and model 3 (adjusted for model 2 plus smoking, alcohol consumption, and $\mathrm{CCl}$ scores) were calculated. Likewise, other subgroup analyses were conducted on the basis of smoking status (nonsmoker and past and current smoker), alcohol consumption ( $<1$ time a week and $\geq 1$ time a week), total cholesterol $(<200, \geq 200$ to $<240$, and $\geq 240$ ), blood pressure (SBP $<140$ and DBP $<90$ and SBP $\geq 140$ or DBP $\geq 90$ ), and fasting blood glucose ( $<100$ and $\geq 100$ ). In these analyses, model 1 , model 2 , and model 3 were also calculated in the same way.

All statistical analyses were performed using SAS version 9.4 (SAS Institute Inc., Cary, NC, USA). Twotailed analyses were performed, and differences with probability values of $<0.05$ were considered statistically significant.

\section{Results}

The general characteristics (age, sex, income, and region of residence) of participants were the same between the two groups due to the matching procedures $(p=1.000)$. Mean total cholesterol level, mean DBP, and the mean number of days of statin prescription did not significantly differ between the AD and control groups ( $p=0.284, p=1.000$, and $p=0.997$, respectively). However, the mean SBP for the AD group $(131.1 \mathrm{mmHg}$ ) was lower than that for the control group $(131.4 \mathrm{mmHg}, p<0.022)$. The mean fasting glucose level $(107.5 \mathrm{mg} / \mathrm{dL})$ and the rate of dyslipidemia $(37.8 \%)$ for the AD group were higher than those for the control group $(103.1 \mathrm{mg} / \mathrm{dL}, 36.1 \%, p<0.001)$. The rate of obesity, smoking status, alcohol consumption, $\mathrm{CCl}$ scores, and the period of statin prescription significantly differed between the $A D$ and control groups $(p<0.001)$. The demographic and clinical characteristics are summarized in Table 1.

The crude OR, which was adjusted only for age, sex, income, and region of residence, and the adjusted OR in model 1, which adjusted dyslipidemia history, total cholesterol, SBP, DBP, and fasting blood glucose for the number of days of statin use per year in the AD group, were $1.00(95 \% \mathrm{Cl} 0.97-1.03, p=0.997)$ and $0.96(95 \% \mathrm{Cl} 0.93-0.99, p=0.003)$, respectively. These results were significant in the adjusted OR in model $2(0.95 ; 95 \% \mathrm{Cl} 0.92-0.98, p=0.003)$, which was adjusted for additional confounders, including obesity, 
smoking, alcohol consumption, and $\mathrm{CCl}$ scores. The crude and adjusted ORs of the number of days of statin use per year in the $A D$ group compared to the control group and subgroup analyses according to age and sex are shown in Table 2.

In subgroup analyses stratified by age and sex, the adjusted OR in model 2 for the number of days of statin use per year was significantly lower in the AD group among women older than 75 years (adjusted OR in model $20.92,95 \% \mathrm{Cl} 0.88-0.97, p=0.002$ ). In addition, the adjusted OR in model 2 for the number of days of statin use per year was lower in the AD group among individuals with high income when subgroup analyses were performed stratified for income (adjusted OR in model $20.95,95 \% \mathrm{Cl}$ 0.91-0.99, $p=0.013)$, and it was lower for all those who lived in urban and rural areas when subgroup analyses were performed stratified for the region of residence (adjusted OR in model 20.95 and $0.96,95 \% \mathrm{Cl} 0.90-0.99$ and $0.92-1.00, p=0.013$ and $p=0.035$, respectively).

In additional subgroup analyses stratified for obesity, smoking status, alcohol consumption, total cholesterol, blood pressure, and fasting blood glucose, the adjusted OR in model 3 was significantly lower in the $A D$ group than in the control group in the subgroups of nonsmokers (adjusted OR in model 30.96 , $95 \% \mathrm{Cl} 0.90-1.00, p=0.011$ ), and individuals with normal weight (adjusted OR in model $30.95,95 \% \mathrm{Cl}$ 0.90-1.00, $p=0.044$ ), alcohol consumption less than once a week (adjusted OR in model $30.96,95 \% \mathrm{Cl}$ 0.92-0.99, $p=0.013$ ), total cholesterol level below 200 (adjusted OR in model $30.94,95 \% \mathrm{Cl} 0.90-0.98, p=$ 0.003), SBP below 140 and DBP below 90 (adjusted OR in model $30.96,95 \% \mathrm{Cl} 0.92-0.99, p=0.019$ ), and fasting blood glucose below 100 (adjusted OR in model $30.94,95 \% \mathrm{Cl} 0.90-0.98, p=0.008$, Additional file 2).

\section{Discussion}

This nested case-control study investigated the association between the number of days of statin use and the occurrence of $A D$ using age-, sex-, income, and region-of-residence-matched cohorts. The main findings of this study demonstrated that the number of days of statin use per year in the AD group was significantly lower than that in the control group, with an adjusted OR of 0.95 (95\% $\mathrm{Cl} 0.92-0.98, p=$ 0.003). This difference was maintained in the subgroup of women older than 75 years. We did not find any differences in the subgroup of men regardless of age and women younger than 75 years when stratified by age and sex. In further stratified analyses of putative risk factors, we found that the association between the number of days of statin use and the occurrence of $A D$ was more prominent in nonsmokers, individuals with normal weight, alcohol consumption below once a week, total cholesterol level below 200, SBP below 140 and DBP below 90, and fasting blood glucose below 100 . It can be inferred that the role of statins in the prevention of $A D$ is more pronounced in relatively low-risk groups than in high-risk groups of $A D$ through further subgroup analyses.

Over the past few years, a large number of observational studies have published a significant association between statin use and a reduced risk of dementia,[16-20] while two randomized controlled trials (RCTs) did not support the hypothesis that statins prevent AD. In the Medical Research Council (MRC) and the 
British Heart Foundation (BHF) Heart Protection Study of 20,536 participants with increased risk for vascular events, evaluations of the effect of simvastatin on dementia risk showed no benefit for dementia prevention.[21] In the Prospective Study of Pravastatin in the Elderly at Risk (PROSPER) trial of 5,804 participants aged 70-82 years with a history of, or risk factors for, vascular disease, pravastatin was found to have no significant effect on cognitive function or disability compared with placebo.[22] Furthermore, a Cochrane Database systematic review of double-blinded, randomized, placebo-controlled trials in which statins were administered for at least 12 months to people at risk of $A D$ and dementia analyzed two trials with 26,340 participants aged 40 to 82 years.[23] This research reported no reduction in the occurrence of $A D$ or dementia in people treated with statins compared to people given placebo and concluded that statins given in late life to people at risk of vascular disease have no role in preventing cognitive decline or dementia. On the other hand, two meta-analyses yielded conflicting results. One systematic review and meta-analysis of 16 studies in qualitative synthesis and 11 in quantitative synthesis examined short- and long-term cognitive effects of statins on patients without a history of cognitive dysfunction and revealed a $29 \%$ reduction in incident dementia in statin-treated patients (hazard ratio, $0.71,95 \% \mathrm{Cl} 0.61-0.82$ ).[24] Another meta-analysis of $25 \mathrm{RCTs}$ reported no effect of statins on cognitive function in a total of 46,836 cognitively healthy and impaired participants.[25] While many studies regarding the effectiveness of statins in treating or preventing $A D$ have shown inconsistent results, our study added evidence to the hypothesis that statin use can contribute to preventing the occurrence of $A D$. The effect of this prevention was greater in individuals with a lower risk of developing dementia than in individuals with a high risk of developing dementia.

The mechanism underlying the association between statin treatment and a reduced risk of $A D$ can be explained by statins' multiple pleiotropic effects. First, statins decrease the inflammatory process, which has beneficial effects in reducing the risk of dementia.[26] Animal models and clinical studies strongly suggest that inflammation contributes to AD pathogenesis.[27] Statins produce an overall antiinflammatory effect by preventing the release of proinflammatory chemokines; matrix metalloproteinases

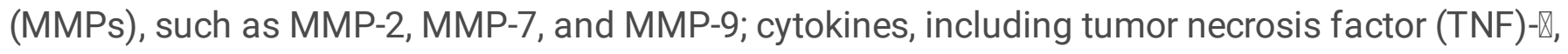
interleukin (IL)-1 $\beta$ and IL-6; and adhesion molecules by inflammatory cells. $[28,29]$ Second, statins may reduce the production of $\beta$-amyloid protein by inhibiting cholesterol biosynthesis to decrease amyloid production.[30-32] $\beta$-Amyloid protein is a neurotoxin and a proteolytic fragment of amyloid precursor protein (APP), which plays a major role in the pathogenesis of AD. Third, statins increase the production of vasodilators such as prostaglandin 12 and the level of endothelial nitric oxide synthase (eNOS) and decrease the production of vasoconstrictors such as angiotensin II, further improving cerebral perfusion. $[33,34]$ In addition, anticoagulation, angiogenesis-promoting effects, and an improvement in vascular endothelial function may enhance cerebral perfusion.[8] Potential neuroprotective benefits from statins can occur by preserving cerebral blood flow, leading to decreased risks of $A D$, since $A D$ is closely associated with cerebral hypoperfusion. Fourth, statins have antioxidant properties as a result of the inhibition of NADPH oxidase, which may contribute to generating an antioxidant effect.[35] These combined effects may exert a beneficial effect that statins might have on preventing AD. In addition, many studies explained that statins do not improve cognition for patients already diagnosed with 
dementia. Likewise, our study showed that this preventive effect of statins on AD was apparent in individuals without baseline medical comorbidities.

\section{Strengths and limitations}

The strengths of this study include the use of NHIS data, which include participants who represent all Korean citizens without exceptions; thus, this cohort is a large, highly representative, nationwide population sample, and there were no missing participants. Due to the substantial number of participants, we could randomly select a control group using 1:4 matching to the AD group by age, sex, income, and region or residence. Moreover, we adjusted our analyses not only for factors affecting the use of statins, such as dyslipidemia history and total cholesterol, but also for other potential confounders, such as obesity, smoking status, alcohol consumption, blood pressure, fasting blood glucose, and $\mathrm{CCl}$ scores.

Nevertheless, several potential limitations should be considered. First, the diagnosis of AD was based on the ICD-10 coding, and there were concerns regarding the accuracy of medical coding in the claims data. To compensate for this limitation, we demonstrated that the coding of AD from NHIS data was shown to have good validity in our previous study (see Supplementary File S1). The diagnosis of AD still remains one primarily based on the clinical history and presentation of the patients as examined by the physician, regardless of the advent of various biomarkers and advanced medical imaging techniques, including molecular imaging. Accordingly, the diagnosis of AD mostly includes a thorough history and a subsequent cognitive function test, such as the Montreal Cognitive Assessment (MoCA) or Mini Mental State Examination (MMSE), and we could not identify whether clinicians have performed the cognitive test in the Korean NIHS database. Subsequently, there is the possibility that AD was underestimated or overestimated. Second, unmeasured confounders such as other putative risk factors for AD were not available for analysis in this study. Although approximately $70 \%$ of the risk of developing $A D$ can be attributed to genetics, we did not consider genetic risk factors. Additionally, well-established acquired factors such as diabetes, hypertension, obesity, smoking, and dyslipidemia were included as confounders; however, information on other acquired factors, including marital status, stress, depression, inadequate sleep, physical activity, diet, vitamin D, and hormonal replacement therapy, was not available in this study. $[36,37]$ Third, AD commonly exists with other comorbidities, such as Lewy body dementia and vascular dementia as a mixed dementia. In the Rochester Epidemiology Project of 419 elderly demented patients, the postmortem diagnosis of $A D$ was established in $51 \%$, of pure vascular dementia in $13 \%$, and of mixed vascular-Alzheimer dementia in the $12 \%$ of patients with "other" diagnosis in the remaining patients.[38] Furthermore, it is evident from autopsy studies that many patients with mixed dementia have both vascular and degenerative causes.[39,40] The three main causes of vascular dementia are large-vessel strokes, small-vessel disease, and microhemorrhages, and the treatment of vascular dementia involves primary and secondary prevention of stroke and cardiovascular disease, which decreases the burden of vascular dementia. Therefore, statins might be effective in preventing not AD but mainly vascular dementia by modifying vascular risk factors in mixed dementia. Finally, several previous studies have suggested that the significant association of statins with AD was robust or limited to lipophilic statins. 
$[17,18]$ Statins are divided into two different subclasses according to their solubility (lipophilic or hydrophilic) and according to their origin and their activity (synthetic or naturally occurring products). Thus, the association between the risk of incident dementia may depend on the different levels of lipid control by specific statins as well as their different properties of blood-brain penetration. However, we did not consider which statins were taken during treatment in this study. It would be necessary to conduct further analysis to determine which statin groups or specific statins are effective in preventing AD.

\section{Conclusion}

Overall, our results indicated the clinical importance of statin use for preventing dementia. The use of statins resulted in greater benefit for women older than 75 years and individuals with a low risk of $A D$ development. Further exploration is warranted to clarify the relationship between statin use and the prevention of $A D$ and confirm this hypothesis.

\section{Abbreviations}

AD: Alzheimer's disease; APP: Amyloid precursor protein; BMI: Body mass index; CCl: Charlson Comorbidity Index; Cl: Confidence interval; DBP: Diastolic blood pressure; eNOS: endothelial nitric oxide synthase; FDA: Food and Drug Administration; HDL: High-density lipoprotein; IL: Interleukin; IRB: Institutional Review Board; LDL: Low-density lipoprotein; MMP: Matrix metalloproteinase; MMSE: Mini Mental State Examination; MoCA: Montreal Cognitive Assessment; NHIS: National Health Insurance Service; OR: Odds ratio; RCT: Randomized controlled trial; SBP: Systolic blood pressure; TNF: Tumor necrosis factor

\section{Declarations}

\section{Acknowledgements}

Not applicable.

\section{Authors' contributors}

JH Kim, HS Lee and JH Wee participated in the interpretation of the data and drafted and revised the manuscript. CY Min and DM Yoo participated in data collection and data interpretation. HG Choi designed the study, participated in data collection and data interpretation, and revised the manuscript. All authors approved the final version of the manuscript for publication.

\section{Funding}

This work was supported in part by a research grant from the National Research Foundation (NRF) of Korea (NRF-2018-R1D1A1A0-2085328 to Hyo Geun Choi; NRF-2018-R1C1B5083040 to Ji Hee Kim).

\section{Availability of data and materials}


The current article used a national sample cohort and does not involve data that can be available.

\section{Ethics approval and consent to participate}

This study was approved by the ethics committee of Hallym University (2019-10-023).

\section{Consent for publication}

Not applicable.

\section{Competing interests}

The authors declare no conflict of interest.

\section{References}

[1] Gorelick PB. Stroke prevention. An opportunity for efficient utilization of health care resources during the coming decade. Stroke 1994;25:220-4.

[2] Mejías-Trueba M, Pérez-Moreno MA, Fernández-Arche MÁ. Systematic review of the efficacy of statins for the treatment of Alzheimer's disease. Clinical Medicine 2018;18:54.

[3] Cummings JL, Morstorf T, Zhong K. Alzheimer's disease drug-development pipeline: few candidates, frequent failures. Alzheimer's research \& therapy 2014;6:1-7.

[4] Daneschvar HL, Aronson MD, Smetana GW. Do statins prevent Alzheimer's disease? A narrative review. European journal of internal medicine 2015;26:666-9.

[5] Li Q, Zhuang Q, Yang J, Zhang Y. Statins excert neuroprotection on cerebral ischemia independent of their lipid-lowering action: the potential molecular mechanisms. Eur Rev Med Pharmacol Sci 2014;18:1113-26.

[6] Power MC, Weuve J, Sharrett AR, Blacker D, Gottesman RF. Statins, cognition, and dementiasystematic review and methodological commentary. Nature Reviews Neurology 2015;11:220.

[7] McGuinness B, Craig D, Bullock R, Passmore P. Statins for the prevention of dementia. Cochrane Database of Systematic Reviews 2009.

[8] Saravi SSS, Saravi SSS, Arefidoust A, Dehpour AR. The beneficial effects of HMG-CoA reductase inhibitors in the processes of neurodegeneration. Metabolic brain disease 2017;32:949-65.

[9] Levine DA, Langa KM. Vascular cognitive impairment: disease mechanisms and therapeutic implications. Neurotherapeutics 2011;8:361. 
[10]Kim SY, Min C, Oh DJ, Choi HG. Tobacco Smoking and Alcohol Consumption Are Related to Benign Parotid Tumor: A Nested Case-Control Study Using a National Health Screening Cohort. Clinical and experimental otorhinolaryngology 2019;12:412.

[11]Kim SY, Min C, Oh DJ, Choi HG. Risk of neurodegenerative dementia in asthma patients: a nested case-control study using a national sample cohort. BMJ open 2019;9:e030227.

[12]Kim SY, Lim J-S, Kong IG, Choi HG. Hearing impairment and the risk of neurodegenerative dementia: a longitudinal follow-up study using a national sample cohort. Scientific reports 2018;8:1-8.

[13]Kim SY, Min C, Oh DJ, Choi HG. Bidirectional association between GERD and asthma: two longitudinal follow-up studies using a national sample cohort. The Journal of Allergy and Clinical Immunology: In Practice 2020;8:1005-13. e9.

[14]Kim SY, Oh DJ, Park B, Choi HG. Bell's palsy and obesity, alcohol consumption and smoking: A nested case-control study using a national health screening cohort. Scientific reports 2020;10:1-8.

[15]Quan H, Li B, Couris C, Fushimi K, Graham P, Hider P, et al. Practice of epidemiology: updating and validating the Charlson comorbidity index and score for risk adjustment in hospital discharge abstracts using data from 6 countries. Am J Epidemiol 2011;173:676-82.

[16]Beydoun MA, Beason-Held LL, Kitner-Triolo MH, Beydoun HA, Ferrucci L, Resnick SM, et al. Statins and serum cholesterol's associations with incident dementia and mild cognitive impairment. J Epidemiol Community Health 2011;65:949-57.

[17]Bettermann K, Arnold AM, Williamson J, Rapp S, Sink K, Toole JF, et al. Statins, risk of dementia, and cognitive function: secondary analysis of the ginkgo evaluation of memory study. Journal of Stroke and Cerebrovascular Diseases 2012;21:436-44.

[18] Haag MD, Hofman A, Koudstaal PJ, Stricker BH, Breteler MM. Statins are associated with a reduced risk of Alzheimer disease regardless of lipophilicity. The Rotterdam Study. Journal of Neurology, Neurosurgery \& Psychiatry 2009;80:13-7.

[19]Cramer C, Haan M, Galea S, Langa K, Kalbfleisch J. Use of statins and incidence of dementia and cognitive impairment without dementia in a cohort study. Neurology 2008;71:344-50.

[20]Sparks DL, Kryscio RJ, Sabbagh MN, Connor DJ, Sparks LM, Liebsack C. Reduced risk of incident AD with elective statin use in a clinical trial cohort. Current Alzheimer Research 2008;5:416-21.

[21]Foundation. MRCBH. MRC/BHF Heart Protection Study of cholesterol lowering with simvastatin in 20,536 high-risk individuals: a randomised placebo-controlled trial. Lancet 2002;360:7-22.

[22]Shepherd J. Blauw gJ, Murphy MB, et al.; PrOSPer study group. PrOspective Study of Pravastatin in the elderly at risk. Pravastatin in elderly individuals at risk of vascular disease (PrOSPer): a randomised 
controlled trial. Lancet 2002;360:1623-30.

[23]McGuinness B, Craig D, Bullock R, Passmore P. Statins for the prevention of dementia. Cochrane Database of Systematic Reviews 2016; doi:10.1002/14651858.CD003160.pub3.

[24]Swiger KJ, Manalac RJ, Blumenthal RS, Blaha MJ, Martin SS. Statins and cognition: a systematic review and meta-analysis of short-and long-term cognitive effects. Mayo clinic proceedings: Elsevier; 2013. p. 1213-21.

[25]Ott BR, Daiello LA, Dahabreh IJ, Springate BA, Bixby K, Murali M, et al. Do statins impair cognition? A systematic review and meta-analysis of randomized controlled trials. Journal of general internal medicine 2015;30:348-58.

[26]Reitz C, Tang M-X, Luchsinger J, Mayeux R. Relation of plasma lipids to Alzheimer disease and vascular dementia. Archives of neurology 2004;61:705-14.

[27]Akiyama H, Barger S, Barnum S, Bradt B, Bauer J, Cole GM, et al. Inflammation and Alzheimer's disease. Neurobiology of aging 2000;21:383-421.

[28]Wanamaker BL, Swiger KJ, Blumenthal RS, Martin SS. Cholesterol, statins, and dementia: what the cardiologist should know. Clinical cardiology 2015;38:243-50.

[29]Wang Q, Yan J, Chen X, Li J, Yang Y, Weng J, et al. Statins: multiple neuroprotective mechanisms in neurodegenerative diseases. Experimental neurology 2011;230:27-34.

[30]Tamboli IY, Barth E, Christian L, Siepmann M, Kumar S, Singh S, et al. Statins promote the degradation of extracellular amyloid $\beta$-peptide by microglia via stimulation of exosome-associated insulin-degrading enzyme (IDE) secretion. Journal of biological chemistry 2010;285:37405-14.

[31]Refolo LM, Pappolla MA, LaFrancois J, Malester B, Schmidt SD, Thomas-Bryant T, et al. A cholesterollowering drug reduces $\beta$-amyloid pathology in a transgenic mouse model of Alzheimer's disease. Neurobiology of disease 2001;8:890-9.

[32]Simons M, Keller P, Dichgans J, Schulz JB. Cholesterol and Alzheimer's disease: is there a link? Neurology 2001;57:1089-93.

[33]Bayorh MA, Ganafa AA, Eatman D, Walton M, Feuerstein GZ. Simvastatin and losartan enhance nitric oxide and reduce oxidative stress in salt-induced hypertension. American journal of hypertension 2005;18:1496-502.

[34]Laufs U, La Fata V, Plutzky J, Liao JK. Upregulation of endothelial nitric oxide synthase by HMG CoA reductase inhibitors. Circulation 1998;97:1129-35. 
[35]Erdös B, Snipes JA, Tulbert CD, Katakam P, Miller AW, Busija DW. Rosuvastatin improves cerebrovascular function in Zucker obese rats by inhibiting NAD $(P) H$ oxidase-dependent superoxide production. American Journal of Physiology-Heart and Circulatory Physiology 2006;290:H1264-H70. [36]Silva MVF, Loures CdMG, Alves LCV, de Souza LC, Borges KBG, das Graças Carvalho M. Alzheimer's disease: risk factors and potentially protective measures. Journal of biomedical science 2019;26:33.

[37]Armstrong RA. Risk factors for Alzheimer's disease. Folia Neuropathol 2019;57:87-105.

[38]Knopman DS, Parisi JE, Boeve BF, Cha RH, Apaydin H, Salviati A, et al. Vascular dementia in a population-based autopsy study. Archives of Neurology 2003;60:569-75.

[39]Jellinger KA. The enigma of vascular cognitive disorder and vascular dementia. Acta neuropathologica 2007;113:349-88.

[40]Korczyn AD. Mixed dementia-the most common cause of dementia. Annals of the New York Academy of Sciences 2002;977:129-34.

\section{Tables}

Table 1 General characteristics of participants 
Characteristics

Age (years old, n, \%)

60-64

65-69

70-74

75-79

80-84

$85+$

$\operatorname{Sex}(n, \%)$

\section{Male}

Female

Income (n, \%)

1 (lowest)

2

3

4

5 (highest)

Region of residence $(n, \%)$

Urban

Rural

Total cholesterol (mg/dL, mean, SD)

SBP (mmHg, mean, SD)

DBP (mmHg, mean, SD)

Fasting blood glucose

(mg/dL, mean, SD)

Obesity $(\mathrm{n}, \%) \ddagger$
Total participants

$A D$

Control

$p$ value

1.000

$951(5.5) \quad 3804(5.5)$

$2212(12.9) \quad 8848(12.9)$

$4237(24.7) \quad 16948(24.7)$

$5311(30.9) \quad 21244(30.9)$

3826 (22.3) $15304(22.3)$

635 (3.7)

2540 (3.7)

1.000

$6742(39.3) \quad 26968$ (39.3)

$10430(60.7) \quad 41720(60.7)$

1.000

$3519(20.5) \quad 14076(20.5)$

1937 (11.3) 7748 (11.3)

$2324(13.5) \quad 9296(13.5)$

3067 (17.9) 12268 (17.9)

$6325(36.8) \quad 25300(36.8)$

1.000

$5986(34.9) \quad 23944$ (34.9)

$11186(65.1) \quad 44744(65.1)$

$197.7(41.5) \quad 197.3(39.5) \quad 0.284$

$131.1(18.0) \quad 131.4(17.2) \quad 0.022 \dagger$

$78.7(11.1) \quad 78.7(10.7) \quad 1.000$

$107.5(38.6) \quad 103.1(29.7) \quad<0.001 \dagger$

$<0.001^{\star}$ 


\begin{tabular}{|c|c|c|c|}
\hline Normal & $6898(40.2)$ & $24979(36.4)$ & \\
\hline Overweight & $4053(23.6)$ & $17587(25.6)$ & \\
\hline Obese I & $4785(27.9)$ & $20969(30.5)$ & \\
\hline Obese II & $494(2.9)$ & $2218(3.2)$ & \\
\hline Smoking status (n, \%) & & & $<0.001^{*}$ \\
\hline Nonsmoker & $13587(79.1)$ & $54537(79.4)$ & \\
\hline Past smoker & $1715(10.0)$ & $7570(11.0)$ & \\
\hline Current smoker & $1870(10.9)$ & $6581(9.6)$ & \\
\hline Alcohol consumption (n, \%) & & & $<0.001^{*}$ \\
\hline$<1$ time a week & $13339(77.7)$ & $51085(74.4)$ & \\
\hline$\geq 1$ time a week & $3833(22.3)$ & $17603(25.6)$ & \\
\hline CCI score (score, $n, \%) \S$ & & & $<0.001^{*}$ \\
\hline 0 & $6256(36.4)$ & $38044(55.4)$ & \\
\hline 1 & $4068(23.7)$ & $13134(19.1)$ & \\
\hline 2 & $2,605(15.2)$ & $7682(11.2)$ & \\
\hline 3 & $1945(11.3)$ & $4459(6.5)$ & \\
\hline$\geq 4$ & $2298(13.4)$ & $5369(7.8)$ & \\
\hline Dyslipidemia (n, \%) & $6485(37.8)$ & $24781(36.1)$ & $<0.001 *$ \\
\hline $\begin{array}{l}\text { The number of days of statin use per year (days, mean, } \\
\text { SD) }\end{array}$ & $\begin{array}{l}114.4 \\
(228.8)\end{array}$ & $\begin{array}{l}114.4 \\
(234.2)\end{array}$ & 0.997 \\
\hline The periods of statin prescription ( $n, \%)$ & & & $<0.001^{*}$ \\
\hline 0 day & $11886(69.2)$ & 49995 (72.8) & \\
\hline$\geq 1$ day $\&<6$ months & $1838(18.7)$ & $5104(7.4)$ & \\
\hline$\geq 6$ months $\&<1$ year & $877(5.1)$ & $3175(4.6)$ & \\
\hline$\geq 1$ year $\&<1.5$ years & $656(3.8)$ & $2234(3.3)$ & \\
\hline$\geq 1.5$ years & 1915 (11.2) & $8180(11.9)$ & \\
\hline
\end{tabular}

Abbreviations: $A D$ Alzheimer's disease, $C C /$ Charlson comorbidity index, $D B P$ diastolic blood pressure, $S B P$ systolic blood pressure, $S D$ standard deviation 
* Chi-square test. Significance at $p<0.05$

† Independent $t$ test. Significance at $p<0.05$

¥ Obesity (BMl, body mass index, $\mathrm{kg} / \mathrm{m}^{2}$ ) was categorized as $<18.5$ (underweight), $\geq 18.5$ to $<23$ (normal), $\geq 23$ to $<25$ (overweight), $\geq 25$ to $<30$ (obese I), and $\geq 30$ (obese II).

$\ddagger \mathrm{CCl}$ scores were calculated for all comorbidities except for dementia.

Table 2 Odds ratios ( $95 \%$ confidence interval) for the days of statin use per year in AD patients compared to control participants with subgroup analyses according to age, sex, income, and region of residence

\begin{tabular}{|c|c|c|c|c|c|c|}
\hline \multirow[t]{2}{*}{ Characteristics } & \multicolumn{6}{|l|}{ Odds ratios } \\
\hline & Crudet & $\begin{array}{l}p \\
\text { value }\end{array}$ & Model 1†‡ & $\begin{array}{l}p \\
\text { value }\end{array}$ & Model 2†§ & $\begin{array}{l}p \\
\text { value }\end{array}$ \\
\hline $\begin{array}{l}\text { Total participants }(\mathrm{n}= \\
85860)\end{array}$ & $\begin{array}{l}1.00(0.97- \\
1.03)\end{array}$ & 0.997 & $\begin{array}{l}0.96(0.93- \\
0.99)\end{array}$ & $0.003^{*}$ & $\begin{array}{l}0.95(0.92- \\
0.98)\end{array}$ & $0.003 *$ \\
\hline $\begin{array}{l}\text { Age }<75 \text { years old, men } \\
(n=14840)\end{array}$ & $\begin{array}{l}1.08(1.01- \\
1.16)\end{array}$ & $0.019 *$ & $\begin{array}{l}1.00(0.92- \\
1.08)\end{array}$ & 0.918 & $\begin{array}{l}1.00(0.92- \\
1.08)\end{array}$ & 0.912 \\
\hline $\begin{array}{l}\text { Age }<75 \text { years old, } \\
\text { women } \\
(n=22160)\end{array}$ & $\begin{array}{l}1.08(1.02- \\
1.13)\end{array}$ & $0.004^{*}$ & $\begin{array}{l}0.98(0.92- \\
1.04)\end{array}$ & 0.420 & $\begin{array}{l}0.98(0.92- \\
1.04)\end{array}$ & 0.487 \\
\hline $\begin{array}{l}\text { Age } \geq 75 \text { years old, } \\
\text { men } \\
(n=18870)\end{array}$ & $\begin{array}{l}0.98(0.93- \\
1.04)\end{array}$ & 0.581 & $\begin{array}{l}0.96(0.90- \\
1.03)\end{array}$ & 0.210 & $\begin{array}{l}0.95(0.89- \\
1.02)\end{array}$ & 0.150 \\
\hline $\begin{array}{l}\text { Age } \geq 75 \text { years old, } \\
\text { women } \\
(n=29990)\end{array}$ & $\begin{array}{l}0.93(0.89- \\
0.97)\end{array}$ & $0.001^{*}$ & $\begin{array}{l}0.92(0.88- \\
0.97)\end{array}$ & $0.002^{\star}$ & $\begin{array}{l}0.92(0.88- \\
0.97)\end{array}$ & $0.002 *$ \\
\hline $\begin{array}{l}\text { Low income }(\mathrm{n}= \\
38900)\end{array}$ & $\begin{array}{l}1.01(0.97- \\
1.05)\end{array}$ & 0.586 & $\begin{array}{l}0.96(0.92- \\
1.01)\end{array}$ & 0.090 & $\begin{array}{l}0.96(0.91- \\
1.00)\end{array}$ & 0.074 \\
\hline $\begin{array}{l}\text { High income }(\mathrm{n}= \\
46960)\end{array}$ & $\begin{array}{l}0.99(0.96- \\
1.03)\end{array}$ & 0.650 & $\begin{array}{l}0.95(0.91- \\
0.99)\end{array}$ & $0.014^{*}$ & $\begin{array}{l}0.95(0.91- \\
0.99)\end{array}$ & $0.013^{*}$ \\
\hline Urban $(n=29930)$ & $\begin{array}{l}0.99(0.95- \\
1.03)\end{array}$ & 0.653 & $\begin{array}{l}0.95(0.90- \\
0.99)\end{array}$ & $0.028^{*}$ & $\begin{array}{l}0.95(0.90- \\
0.99)\end{array}$ & $0.029 *$ \\
\hline Rural (n = 55930) & $\begin{array}{l}1.01(0.97- \\
1.04)\end{array}$ & 0.717 & $\begin{array}{l}0.96(0.92- \\
1.00)\end{array}$ & $0.044^{*}$ & $\begin{array}{l}0.96(0.92- \\
1.00)\end{array}$ & $0.035^{\star}$ \\
\hline
\end{tabular}

Abbreviations:CC/Charlson comorbidity index, DBP diastolic blood pressure, SBP systolic blood pressure 
* Conditional logistic regression, Significance at $p<0.05$

† Models were stratified by age, sex, income, and region of residence.

‡ A model 1 was adjusted for dyslipidemia history, total cholesterol, SBP, DBP, and fasting blood glucose.

‡ A model 2 was adjusted for model 1 plus obesity, smoking, alcohol consumption, and CCI scores.

\section{Figures}

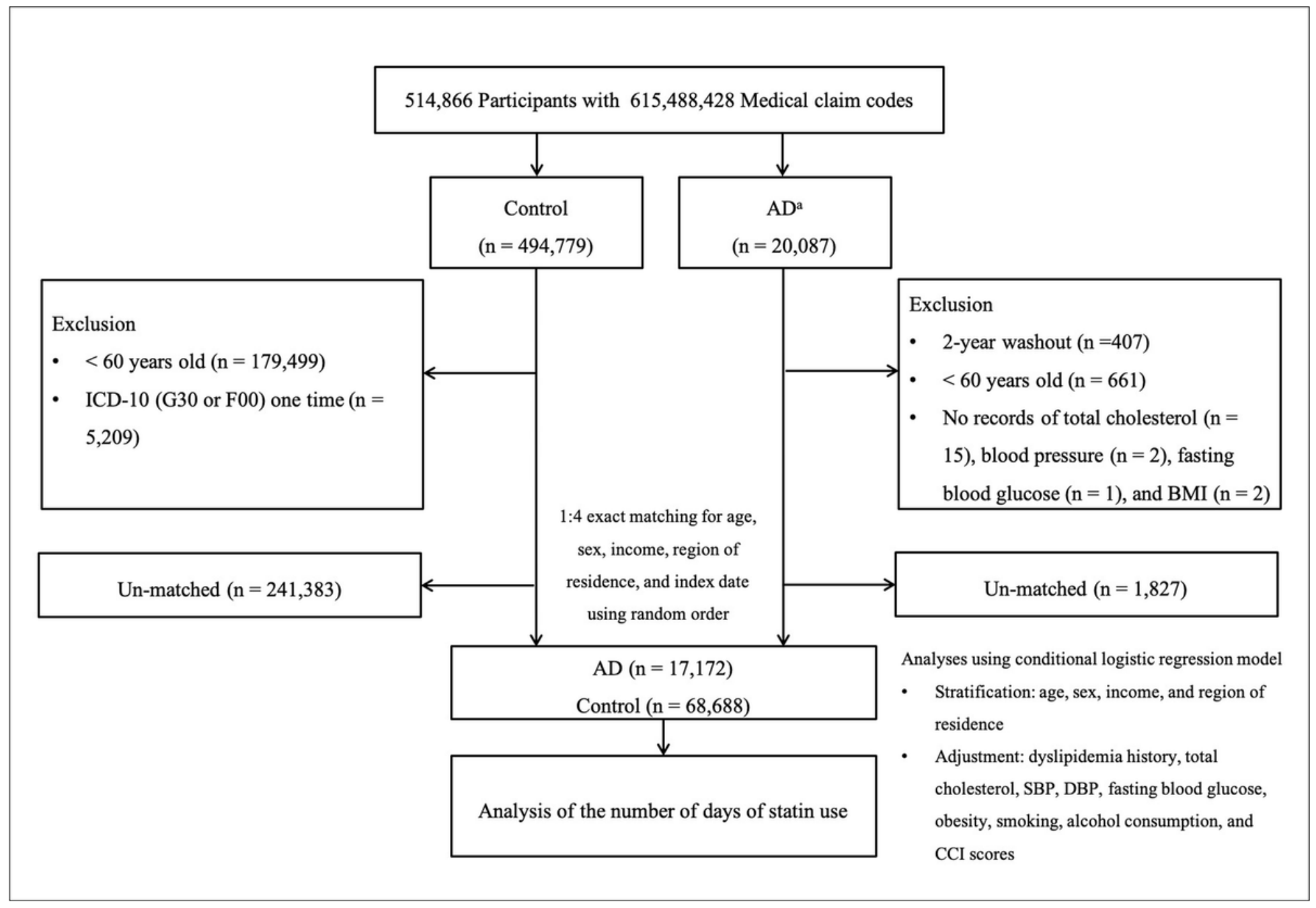

Figure 1

A schematic illustration of the participant selection process used in this study. Of the total 514,866 participants, 17,172 of AD patients were matched with 68,688 control participants for age, sex, income, and region of residence. Abbreviations: $\mathrm{AD}$, Alzheimer's disease; $\mathrm{BMI}$, Body mass index; $\mathrm{CCl}$, Charlson Comorbidity Index; DBP, Diastolic blood pressure; SBP, Systolic blood pressure. "a" indicates that AD patients were selected as the participants assigned G30 or F00 based on ICD-10 codes $\geq 2$ times. 
Subgroups

Obesity

Underwight

Normal weight

Overweight

Obese

Smoking

Nonsmoker

Past and current smoker

Alcohol consumption

$<1$ time a week

$\geq 1$ time a week

Total Choldesterol (mg/dL)

$<200$

$\geq 200$ to $<\mathbf{2 4 0}$

$\geq 240$

Blood pressure (mmHg)

SBP $<140$ and $\mathrm{DBP}<90$

SBP $\geq 140$ or $\mathrm{DBP} \geq 90$

Fasting blood glucose (mg/dL)

$<100$

$\geq 100$
$0.94(0.90-0.98)$

$\operatorname{aOR}(95 \% \mathrm{CI})$

$1.08(0.89-1.31)$

$0.95(0.90-1.00)$

0.94 (0.89-1.00)

$0.96(0.91-1.01)$

$0.96(0.92-0.99)$

$0.94(0.88-1.01)$

$0.96(0.92-0.99)$

$0.94(0.88-1.00)$

$0.94(0.90-0.98)$

$0.94(0.88-1.00)$

$0.97(0.89-1.06)$

$0.96(0.92-0.99)$

$0.95(0.90-1.00)$

$0.96(0.92-1.01)$

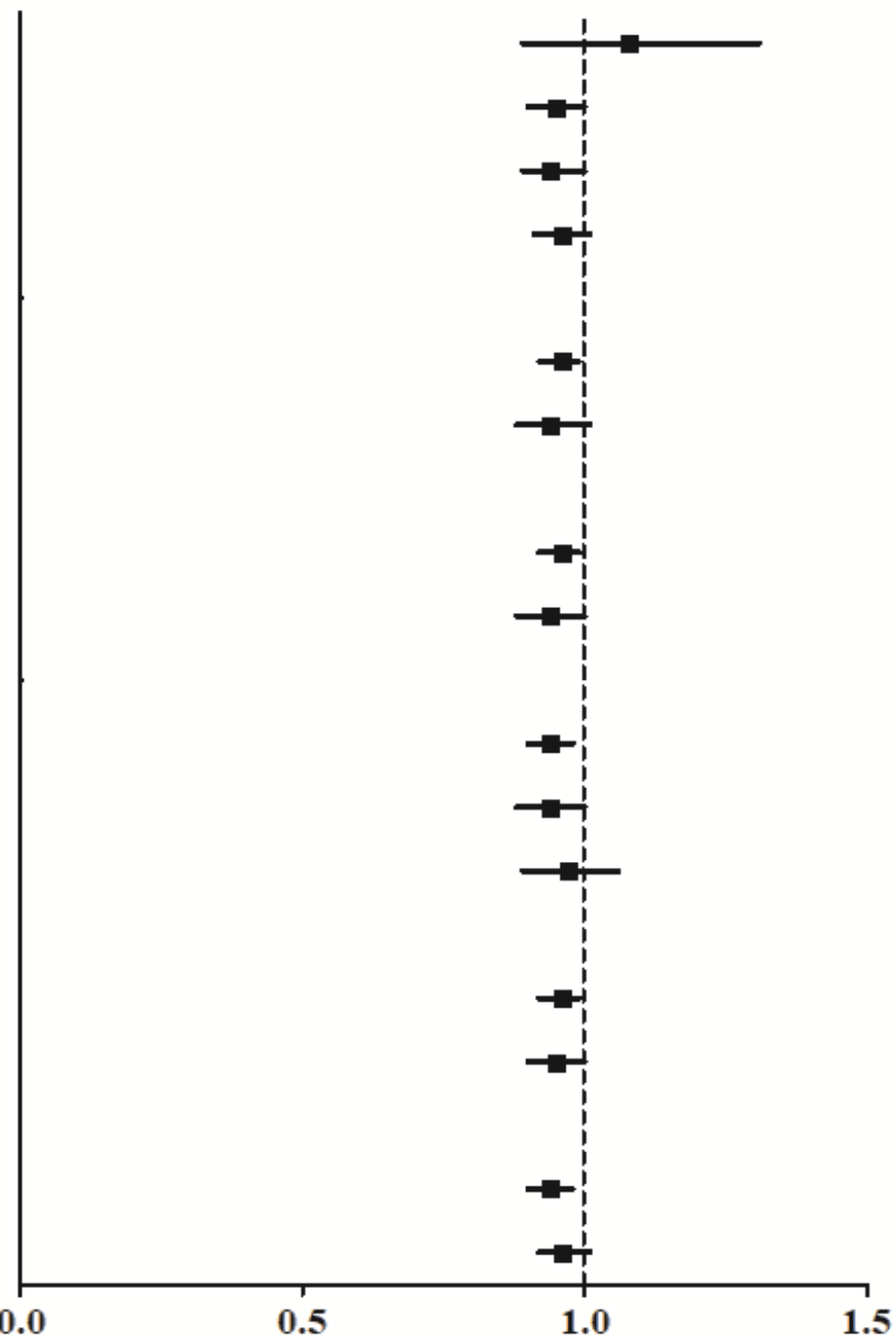

Adjusted odds ratio ( $95 \%$ confidence interval)

Figure 2

Adjusted odds ratios and $95 \%$ confidence intervals for the days of statin use per year in AD patients compared to control participants according to various comorbidities. Abbreviations: AD, Alzheimer's disease; Cl, Confidence interval; DBP, Diastolic blood pressure; OR, Odds ratio; SBP, Systolic blood pressure.

\section{Supplementary Files}

This is a list of supplementary files associated with this preprint. Click to download.

- Additionalfile1.docx

- Additionalfile2.docx 